\title{
Taphonomic analysis of large mammals recovered from the Pleistocene Rancho La Brea tar seeps
}

\author{
Lillian M. Spencer, Blaire Van Valkenburgh, and John M. Harris
}

\begin{abstract}
The asphalt deposits of Rancho La Brea are well known for preserving a prolific and diverse Late Pleistocene fauna. However, little taphonomic research has been done on these collections. To better understand the formation of this impressive assemblage, a taphonomic study of the bones of the large mammals from one asphalt deposit, Pit 91, was carried out, and results are presented here. The predominance of carnivore specimens in the Rancho La Brea deposits has long been explained by a scenario in which a prey animal was trapped in asphalt and attracted large numbers of carnivores who became trapped in turn. Hypotheses generated from this scenario were tested by collecting taphonomic data on over 18,000 specimens. Weathering data indicate that elements were deposited fairly rapidly. However, patterns of skeletal part representation for the seven most common species demonstrate that complete skeletons are not present. Water transport is ruled out as the primary process responsible for removing skeletal elements based on abrasion data. Instead, the feeding activity of carnivores (ravaging) appears to have been an important factor in the formation of the assemblage.
\end{abstract}

Lillian M. Spencer. Department of Anthropology, Post Office Box 173364, University of Colorado at Denver, Denver, Colorado 80217-3364.E-mail: lspencer@carbon.cudenver.edu

Blaire Van Valkenburgh. Department of Organismic Biology, Ecology, and Evolution, 621 Young Drive,

South, University of California at Los Angeles, Los Angeles, California 90095-1606

John M. Harris. George C. Page Museum, Los Angeles, California 90036

Accepted: 24 March 2003

\section{Introduction}

The Pleistocene deposits of Rancho La Brea are world famous for the volume of prehistoric material recovered from them. Millions of specimens ranging in age from 44,000 to 4000 B.P. have been excavated from these deposits over the course of the last 100 years (Marcus and Berger 1984; Stock and Harris 1992). Not only is the material very abundant, but it is also extremely diverse. Representing over 500 species, specimens range in size from insects to mammoth long bones, all well preserved (Akersten et al. 1983; Harris and Jefferson 1985).

The excellent nature of the preservation at Rancho La Brea is due to the sediments from which specimens are recovered-asphalt-impregnated layers of sand or clay, distributed across an approximately 23-acre area of Los Angeles, California (Woodard and Marcus 1973; Stock and Harris 1992). The sediments were laid down in the late Pleistocene as broad alluvial fans derived from the nearby Santa Monica Mountains (Akersten et al. 1983; Shaw and Quinn 1986; Quinn 1992). Ephem- eral streams deposited the sediments that contain the majority of the bones (Shaw and Quinn 1986). Portions of these sediments were permeated by petroleum that seeped upward from deeper, more ancient Tertiary oil sands through strata fractured by movement within the earth's crust (Woodard and Marcus 1973; Shaw and Quinn 1986). In some cases the petroleum reached the surface, and, as the lighter petroleum portion evaporated, sticky pools of natural asphalt were left behind (Akersten et al. 1983). The vertebrate skeletal material is also impregnated with asphalt, which acts to preserve it in its original state (Shaw and Quinn 1986). This process, which continues today, was in progress by at least 45,000 years ago, when animals and plants were mired in these sticky pools and subsequently buried in sediments of the alluvial plain (Harris and Jefferson 1985; Shaw and Quinn 1986; Quinn 1992). In addition to entrapment, bones were also concentrated in the area by fluviatile action (Quinn 1992).

What happened to these mammals after they became trapped in the asphalt and before their excavation? Almost all of the skeletons 
are entirely disarticulated, obscuring our view of what occurred after death. The question of taphonomic processes in action at Rancho La Brea has only been minimally addressed (Gilbert 1927; Stock 1929; Miller 1969; Scott 1989), and yet a complete understanding of these processes is critical to further paleobiological studies of the collections (Akersten et al. 1983). Without an understanding of the biases that affected preservation, it is premature to use the collections for paleoecological and evolutionary studies. Here, we report on research undertaken to investigate which taphonomic processes affected the Rancho La Brea collection. One reason for the paucity of taphonomic studies at Rancho La Brea is that much of the material was collected before 1930, when excavation techniques were less thorough than is typical today. The preference at that time was for large, complete bones, and little attention was paid to collecting positional or other data (Shaw and Quinn 1986). More recent excavations have addressed this problem. Since 1969, the Los Angeles County Museum of Natural History has been excavating Pit 91, one of the asphalt deposits located in Hancock Park (Shaw 1982). Over 40,000 specimens collected between 1969 and 1980 have been identified and cataloged into a computer database, each with three-dimensional positional information. This collection is the focus of the research presented here.

One of the more unusual aspects of the La Brea faunal collection is the dominance of carnivores (Shaw and Quinn 1986; Stock and Harris 1992). Over $90 \%$ of the large mammalian specimens recovered represent members of the order Carnivora (Marcus 1960). This is certainly not the case in living communities, in which carnivores are at the top of the food pyramid and thus are much less abundant than herbivores (Eisenberg 1981). It has been suggested that the disproportionate abundance of carnivores is a result of the following scenario: a single herbivore became trapped in the asphalt and attracted numerous carnivores, some of which were trapped in turn. Such an event need only have occurred once every ten years or so over the course of 30,000 years to account for all the large mammals in the entire collection (Shaw and Quinn 1986; Stock and Harris 1992).

To investigate taphonomic processes affecting the Rancho La Brea fauna, we explored several hypotheses. First, because the asphalt seeped out through vents, forming a layer of unknown thickness that covered the ground instead of a deep pit, it is possible that the skeletons were exposed for a significant period of time, rather than being quickly submerged in the asphalt. Our first hypothesis is that the bones are likely to exhibit relatively high weathering stages (Behrensmeyer 1978) due to exposure. Second, reconstruction of some of the sediments as deposited by fluviatile action suggests that fluvial transport affected the assemblages. If so, then we expect that the majority of the bones' surfaces will exhibit signs of abrasion.

A third set of hypotheses is based on a variety of patterns relating to the effects of carnivores on bone deposits. The predominance of carnivores and the high incidence of carnivore teeth fractured in life (Van Valkenburgh and Hertel 1993) suggest that carnivore modification of carcasses ("ravaging") might have significantly destroyed and dispersed the skeletal assemblages as well. Actualistic studies of bone-modifying behaviors in gray wolves (C. lupus) (Haynes 1982, 1983; D'Andrea and Gotthardt 1984) and spotted hyenas (Crocuta crocuta) (Blumenschine 1986, 1988; Marean and Spencer 1991) indicate that it is possible to predict expected patterns of bone modification and skeletal representation if carnivore activity was involved. Both these species are appropriate models for this analysis because they share some similarities with dire wolves (Canis dirus), a dominant carnivore in the Pit 91 assemblage. Gray wolves are closely related to dire wolves and morphologically similar in many ways, but the slightly more robust dentition of dire wolves indicates greater bone-crushing abilities (Stock and Harris 1992), and thus spotted hyenas are an appropriate analog as well. It is likely that the bone-modifying behaviors of dire wolves were intermediate between those of extant wolves and spotted hyenas. Sabertooth cats (Smilodon fatalis) are also abundant in Pit 91, and their feeding activities could also have 
modified the fossil sample in some way (Miller 1969), though their postcanine dentition is unsuited for bone crushing (Marean and Ehrhardt 1995).

Both wolves and spotted hyenas tend to leave the skulls and mandibles of their prey behind, but they often remove entire limbs, especially from the upper exposed side of the carcass (Haynes 1982; D'Andrea and Gotthardt 1984; Blumenschine 1986, 1988). They both tend to favor bones that are less dense and contain significant amounts of bone grease and marrow (Haynes 1980, 1982; Blumenschine 1988; Marean and Spencer 1991; Marean et al. 1992). Evidence of their feeding activity can be significant, with $50 \%$ to more than $70 \%$ of all bones showing tooth marks (D'Andrea and Gotthardt 1984; Blumenschine 1988).

In view of these general patterns, we generated a group of hypotheses concerning carnivore modification of the Pit 91 sample: if carnivore ravaging was significant, then (1) skulls and mandibles should be relatively common elements; (2) limb bones should only be present half as often as expected; and (3) bone density and element frequency should be correlated, because carnivores will preferentially carry away and/or consume the least dense elements of a skeleton. However, because a tar seep is not the same context as a kill site, and carnivores probably did not consume carcasses on site, we predict that (4) bones recovered from the tar seep will be relatively complete, and that (5) tooth mark frequencies will be low. These hypotheses were tested through examination of skeletal part representation and carnivore modification.

\section{Materials and Methods}

Sample

To investigate the taphonomic processes that affected the bone collections at Rancho La Brea, we examined a large subset of the cataloged material from the 1969-1980 excavation of Pit 91. Although not all the material from this excavation has been cataloged, we assume that our subset of 18,498 specimens is representative of the entire collection. Elements that might be underrepresented include small el- ements such as phalanges, because some of these elements have yet to be prepared and cataloged. Consequently, our major conclusions are based on the relative representation of limbs and crania rather than smaller elements. Our subset of 18,498 specimens consisted of material from mammals estimated to have weighed more than $5 \mathrm{~kg}$. Small mammals and nonmammalian species were not included because the smaller, more delicate bones experience different taphonomic processes than bones from larger species. Also excluded from this subset were individual teeth, sesamoid bones, and sloth osteoderms, because none of these element types typically exhibit any surface modification. Table 1 lists the taxa included in this sample, and the number of identified specimens (NISP) for each taxon.

\section{Data Collection and Analysis}

For each cataloged specimen, several variables were recorded. These included taxonomic information (order, family, genus and species) and skeletal part (element, side, and, if known, whether the specimen comes from an adult or a juvenile). Also recorded was whether a specimen was complete or partial, and if partial, what portion of the element was present. For example, for all long bones the presence or absence of the following portions was recorded: proximal epiphysis, proximal shaft, midshaft, distal shaft, and distal epiphysis. This information allowed us to generate reasonably accurate MNE (minimum number of element) counts because they were based on the most common portion. Finally, we recorded a variety of taphonomic variables, including weathering, abrasion, pit wear, rodent and insect modification, and carnivore modification. Three of these variables are discussed here:

Weathering.-Bones exposed to the elements experience exfoliation, cracking, and splitting (Miller 1975; Fisher 1995). Behrensmeyer (1978) demonstrated that bones lying on the land surface pass through distinct weathering stages. Stage 0: bone surface shows no sign of cracking or flaking; Stage 1: bone surface shows cracking; Stage 2: outermost layers of bone surface show flaking, and deeper cracking; Stage 3: bone surface has large patches of 
TABLE 1. Taxonomic information for the Pit 91 sample examined for this project.

\begin{tabular}{|c|c|c|c|c|}
\hline Order & Family & Genus & Species & NISP \\
\hline Artiodactyla & & & & 28 \\
\hline Artiodactyla & Antilocapridae & & & 8 \\
\hline Artiodactyla & Antilocapridae & Antilocapra & americana & 10 \\
\hline Artiodactyla & Antilocapridae & Capromeryx & & 3 \\
\hline Artiodactyla & Antilocapridae & Capromeryx & minor & 71 \\
\hline Artiodactyla & Bovidae & & & 15 \\
\hline Artiodactyla & Bovidae & Bison & & 1 \\
\hline Artiodactyla & Bovidae & Bison & antiquus & 1002 \\
\hline Artiodactyla & Bovidae & Bison & occidentalis & 2 \\
\hline Artiodactyla & Camelidae & & & 2 \\
\hline Artiodactyla & Camelidae & Camelops & & 1 \\
\hline Artiodactyla & Camelidae & Camelops & hesternus & 38 \\
\hline Artiodactyla & Cervidae & & & 7 \\
\hline Artiodactyla & Cervidae & Odocoileus & hemionus & 21 \\
\hline Artiodactyla & Tayassuidae & Platygonus & & 2 \\
\hline Carnivora & & & & 22 \\
\hline Carnivora & Canidae & & & 10 \\
\hline Carnivora & Canidae & Canis & & 36 \\
\hline Carnivora & Canidae & Canis & dirus & 6666 \\
\hline Carnivora & Canidae & Canis & latrans & 1213 \\
\hline Carnivora & Canidae & Canis & lupus & 6 \\
\hline Carnivora & Canidae & Urocyon & & 1 \\
\hline Carnivora & Felidae & & & 30 \\
\hline Carnivora & Felidae & Felis & & 19 \\
\hline Carnivora & Felidae & Felis & concolor & 29 \\
\hline Carnivora & Felidae & $\operatorname{Lyn} x$ & rufus & 17 \\
\hline Carnivora & Felidae & Panthera & atrox & 188 \\
\hline Carnivora & Felidae & Smilodon & & 2 \\
\hline Carnivora & Felidae & Smilodon & fatalis & 7312 \\
\hline Carnivora & Ursidae & & & 9 \\
\hline Carnivora & Ursidae & Arctodus & & 1 \\
\hline Carnivora & Ursidae & Arctodus & simus & 86 \\
\hline Carnivora & Ursidae & Ursus & & 2 \\
\hline Carnivora & Ursidae & Ursus & arctos & 4 \\
\hline Edentata & & & & 6 \\
\hline Edentata & Megatheriidae & & & 4 \\
\hline Edentata & Megatheriidae & Nothrotheriops & shastense & 52 \\
\hline Edentata & Mylodontidae & & & 1 \\
\hline Edentata & Mylodontidae & Paramylodon & harlani & 386 \\
\hline Herbivore & & & & 96 \\
\hline Herbivore? & & & & 2 \\
\hline Mammalia & & & & 204 \\
\hline Pecora & & & & 1 \\
\hline Perissodactyla & & & & 3 \\
\hline Perissodactyla & Equidae & & & 14 \\
\hline Perissodactyla & Equidae & Equus & & 14 \\
\hline Perissodactyla & Equidae & Equus & occidentalis & 835 \\
\hline Perissodactyla & Tapiridae & Tapirus & californicus & 1 \\
\hline Proboscidea & & & & 5 \\
\hline Proboscidea & Mammutidae & Mammut & americanum & 4 \\
\hline \multirow[t]{2}{*}{ Unknown } & & & & 6 \\
\hline & & & Total: & 18,498 \\
\hline
\end{tabular}

rough bone, from which the outermost surface layer has been removed; Stage 4: bone surface is coarsely fibrous and rough, splinters may be present; Stage 5: bone is falling apart, with large splinters missing, and deep cracking is present. For this study, each specimen was examined and assigned to one of these weath- ering stages. Because different bones of the skeleton weather at different rates, as do bones of different-sized animals (Behrensmeyer 1978), the sample is subdivided into categories of element and taxon.

Abrasion.-Abrasion is commonly defined as the erosion of the bone surface due to the 
physical impact of sedimentary particles (Bromage 1984; Lyman 1994; Shipman and Rose 1988). It can occur both in water and on land, though it is much more common in water (Lyman 1994). Often, abrasion can result in a smooth, rounded, and polished surface (Fisher 1995). The erosion of the smooth outer bone surface, however, usually results in a rough texture being exposed. In this study, the degree of abrasion was recorded as follows. Absent: no erosion of surface bone; Minimal: slight erosion at one or two points on the bone; Light: less than $25 \%$ of the bone surface shows erosion; Moderate: between 25 and $50 \%$ of the bone surface shows erosion; Heavy: more than $50 \%$ of the bone surface shows erosion. The presence of a smooth polished surface was also noted.

Carnivore Modification.-Using strong directional lighting, and a low-power microscope when desirable (as advocated in Blumenschine et al. 1996), we carefully inspected every specimen for any kind of surface modification. Three categories of tooth marks were assessed: (1) scores, which are small marks (either circular or linear) with shallow cross-sections; (2) punctures, in which the bone has collapsed under the pressure of the tooth leaving a circular hole in the bone surface; and (3) notches, in which a semicircular-shaped flake is missing from the edge of a bone (Blumenschine 1988). If there were no scores, then a classification of Absent was recorded; one to five scores was recorded as Light; six to ten scores was recorded as Moderate; more than ten scores was recorded as Heavy. For punctures and notches, counts were made and the number of these kinds of modifications was recorded.

Patterns of abrasion, weathering, and carnivore modification present in the skeletal assemblage were summarized by assessing overall frequency (percentage of bones with modification), frequency of different types and levels of modification, and distribution of modified bones by element and species.

Skeletal Part Representation.-The assessment of skeletal part representation was restricted to the most common seven species from the assemblage, which make up more than $98 \%$ of the total sample. Table 2 lists these species and
TABLE 2. The seven most common taxa in the sample of specimens from Pit 91 examined in this study. Minimum number of individuals (MNI) is provided for both adults and juveniles.

\begin{tabular}{lrcc}
\hline \hline \multicolumn{1}{c}{ Taxon } & NISP & $\begin{array}{c}\% \text { Total } \\
\text { sample }\end{array}$ & $\begin{array}{c}\text { MNI } \\
\text { (adult/juv) }\end{array}$ \\
\hline Smilodon fatalis & 7312 & $41 \%$ & $73(53 / 20)$ \\
Canis dirus & 6666 & $37 \%$ & $56(40 / 16)$ \\
Canis latrans & 1213 & $7 \%$ & $16(10 / 6)$ \\
Bison antiquus & 1002 & $6 \%$ & $12(5 / 7)$ \\
Equus occidentalis & 835 & $5 \%$ & $13(6 / 7)$ \\
Paramylodon harlani & 386 & $2 \%$ & $6(4 / 2)$ \\
Panthera atrox & 188 & $1 \%$ & $6(4 / 2)$ \\
\hline
\end{tabular}

the minimum number of individuals (MNI) for both adults and juveniles. This sample contains three herbivorous species, all of large $(>300 \mathrm{~kg}$ ) body size: Equus occidentalis, the western horse; Bison antiquus, the ancient bison; and Paramylodon harlani, Harlan's ground sloth. The scarcity of small and medium-sized herbivores suggests that these size classes of herbivores were not well represented in the Los Angeles basin some 30,000 years ago. There is no size bias in the modern collection methods for Pit 91, and the four carnivorous species range in body size from the small coyote (Canis latrans) through the medium-sized dire wolf (C. dirus) to the large sabertooth cat (Smilodon fatalis) and North American lion (Panthera atrox).

Skeletal part representation was determined by generating MNE counts for each element of the skeleton. The purpose of this was to assess how complete skeletal representation was for each species. MNE is the minimum number of a particular skeletal element or portion of an element (Lyman 1994). It is a quantitative unit that is useful for illustrating differences between what is found in the paleontological assemblage and the set of skeletal elements found in a complete skeleton. Here, MNE was derived by adding together all the counts for each recorded element portion. Using Equus humeri as an example, a NISP of 20 comprised four proximal epiphyses, six proximal shafts, 15 midshafts, 14 distal shafts, and eight distal epiphyses. The MNE is the number of the highest portion, so we recorded an MNE of 15 , based on the midshafts represented in this sample. The age of the individ- 
ual or side of the element is not taken into account to generate MNEs.

The MNE data (Table 3) were used to generate MAU (minimum animal unit) and $\%$ MAU values. To generate MAU values, the MNE for each element was divided by the number of times that element appears in a skeleton (e.g., humerus = 2). For each species, the MAU values were then standardized by dividing each MAU value by the greatest MAU value. In the Equus example, the axis yielded the highest MAU value, eight, and so the MAU of each element was divided by eight. The humerus thus had a \%MAU value of $94 \%$, showing that the survivorship of the humerus midshaft was very high relative to the most common element, the axis. The \%MAU values for the seven most common taxa are listed in Table 4.

To assess whether patterns of skeletal part representation are mediated by such factors as bone density and the quantity of within-bone nutrients (e.g., marrow, grease), \%MAU values of Bison and Equus limb element portions were plotted against structural density data for extant bovids (wildebeest, Connochaetes taurinus) and horses (Equus sp.) (Lam et al. 1998), and against bone grease or marrow cavity volume data for Bison and Equus (Brink 1997; Outram and Rowley-Conwy 1998). Unfortunately, comparable density data and within-bone nutrient data do not exist for Paramylodon or any carnivores.

\section{Results}

Weathering.-The overwhelming majority of the specimens (93\%) are in Stages 0-2, showing either no weathering or some cracking and exfoliation of the outermost bone surface (Table 5). This pattern is consistent across different subsets of the sample, whether it is broken down by taxon, by element, or by age. Very few bones display Stage 5, yet these heavily weathered specimens are from four different species and were scattered throughout the deposit, so they do not represent a coherent group. Clearly, the large mammal bones from Pit 91 were buried fairly rapidly.

Abrasion.-Almost half of the specimens $(48 \%)$ show no or minimal erosion of the surface bone (Table 6). Only $14 \%$ of the specimens show moderate or heavy degrees of abrasion, in which more than $25 \%$ of the bone surface shows erosion. This pattern is consistent across different subcategories, including both bone type and mammalian order. However, when the sample is broken down by age, there is a shift in the frequencies for bones from juvenile individuals. The number of juvenile specimens showing moderate or heavy degrees of abrasion increases to $24 \%$. It seems likely that the spongier nature of juvenile bone is more vulnerable to the effects of abrasion. Only $4 \%$ of the entire sample has a smooth polish and the rounded edges characteristic of water transport. Because almost half of the specimens examined show no or minimal abrasion, it is likely that fluvial transport did not significantly influence the composition of the Pit 91 bone assemblage.

Carnivore Modification.-As we predicted, very few specimens, $2 \%$ of the total sample, show carnivore modification. The number of specimens exhibiting carnivore scores is low $(n=243)$, and the majority of these show light scoring (Table 7). The same pattern is found for the other categories of carnivore modification. The number of specimens that have notches is lower $(n=136)$, and the number of specimens that show carnivore punctures is lower still $(n=95)$.

Limb bones, ribs, and vertebrae make up the majority of elements that show carnivore modification (Table 7). Specimens that show carnivore modification come from a variety of taxa (Table 8). In raw numbers, the most common taxa in the total sample also show the highest frequency of carnivore modification (bison, dire wolf, and sabertooth cat). However, when these values are scaled to NISPs, it is specimens that cannot be identified to genus that show higher frequencies of carnivore modification (Pecora, Edentata, Unknown, and Cervidae). These specimens cannot be identified to genus because they are so fragmentary, suggesting that these bones were intensively modified by carnivores at or near the tar seep.

Skeletal Part Representation.-If complete or mostly complete skeletons were recovered for the seven most common species, then most of the \%MAU values in Table 4 would be at or 


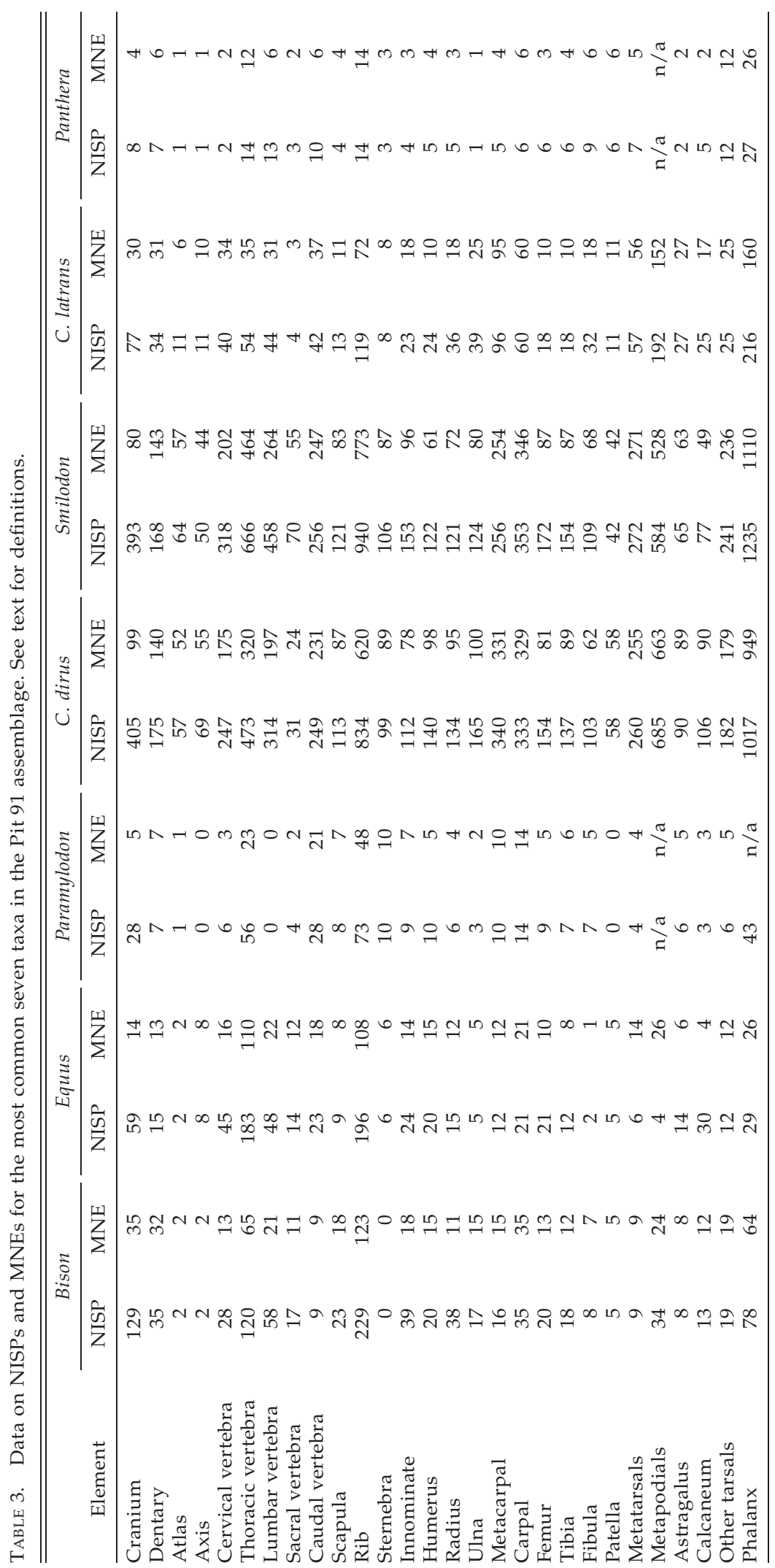


TABLE 4. Skeletal part representation data (\%MAU) for the seven most common taxa. Each value represents the MAU scaled to the element that had the highest MAU value, to indicate the completeness of the skeletal remains.

\begin{tabular}{|c|c|c|c|c|c|c|c|}
\hline Element & Bison & Equus & Paramylodon & Smilodon & C. dirus & C. latrans & Panthera \\
\hline Cranium & 100 & 88 & 71 & 100 & 71 & 97 & 100 \\
\hline Dentary & 91 & 81 & 100 & 89 & 100 & 100 & 75 \\
\hline Atlas & 11 & 25 & 29 & 71 & 74 & 39 & 25 \\
\hline Axis & 11 & 100 & 0 & 55 & 79 & 65 & 25 \\
\hline Cervical & 15 & 40 & 17 & 50 & 50 & 44 & 10 \\
\hline Thoracic & 27 & 76 & 41 & 44 & 35 & 17 & 23 \\
\hline Lumbar & 24 & 46 & 0 & 47 & 40 & 29 & 21 \\
\hline Sacral & 13 & 21 & 6 & 23 & 11 & 6 & 17 \\
\hline Caudal & 3 & 12 & 29 & 24 & 16 & 11 & 6 \\
\hline Scapula & 51 & 50 & 100 & 52 & 62 & 35 & 50 \\
\hline Rib & 25 & 38 & 26 & 37 & 34 & 18 & 13 \\
\hline Sternebra & 0 & 9 & 41 & 14 & 16 & 6 & 9 \\
\hline Innominate & 51 & 88 & 100 & 60 & 56 & 58 & 38 \\
\hline Humerus & 43 & 94 & 71 & 38 & 70 & 32 & 50 \\
\hline Radius & 31 & 75 & 57 & 45 & 68 & 58 & 38 \\
\hline Ulna & 43 & 31 & 29 & 50 & 71 & 81 & 13 \\
\hline Metacarpal & 43 & 75 & 29 & 32 & 47 & 61 & 10 \\
\hline Carpal & 17 & 19 & 29 & 31 & 34 & 28 & 11 \\
\hline Femur & 37 & 63 & 71 & 54 & 58 & 32 & 38 \\
\hline Tibia & 34 & 50 & 86 & 54 & 44 & 32 & 50 \\
\hline Fibula & 20 & 6 & 71 & 42 & 64 & 58 & 75 \\
\hline Patella & 14 & 31 & 0 & 26 & 41 & 35 & 75 \\
\hline Metatarsal & 26 & 88 & 14 & 42 & 46 & 45 & 16 \\
\hline Astragalus & 23 & 38 & 71 & 39 & 64 & 87 & 25 \\
\hline Calcaneum & 34 & 25 & 43 & 30 & 64 & 55 & 25 \\
\hline Other tarsal & 18 & 19 & 18 & 29 & 26 & 16 & 30 \\
\hline Phalanx & 15 & 27 & $\mathrm{n} / \mathrm{a}$ & 27 & 24 & 18 & 13 \\
\hline
\end{tabular}

close to 100. However, examination of Table 4 shows that for each species there are many elements missing, relative to the most common element recovered for each (see also Fig. 1). Among the seven species, Bison shows the most missing elements, with all but two of the elements showing \%MAU values at or below $50 \%$. The two cranial elements, cranium and dentary, are the most common, and small elements such as sternebrae and caudal vertebrae are almost completely absent. In contrast to Bison, Equus shows better survival of elements, with many \%MAU values above $75 \%$. Those elements that tend to be underrepresented in the Equus sample are small bones such as fibulae, sternebrae, and caudal vertebrae. Paramylodon shows a pattern of \%MAU values intermediate between Bison and Equus. The innominate, scapula, and dentary all yield values of $100 \%$, and six other elements (cranium, humerus, femur, tibia, fibula, and astragalus) have \%MAU values between 50 and $75 \%$.

Among the carnivores, the dire wolf shows the most complete pattern of skeletal repre- sentation. $C$. dirus has \%MAU values that fall between $50 \%$ and $75 \%$ for most of the appendicular bones, whereas bones of the axial skeleton (ribs, sternebrae, and vertebrae) tend to be underrepresented, although not to the extent seen in Bison. For C. latrans, cranium, dentary, astragalus, and ulna are well represented, with \%MAU values over $75 \%$. Underrepresented elements include thoracic, lumbar, sacral, and caudal vertebrae, and sternebrae. Smilodon exhibits a fairly even pattern of representation, with most of the elements showing \%MAU values between 30 and $60 \%$. The elements that are most underrepresented are sternebrae and the small vertebrae. Finally, Panthera specimens are not common in the assemblage, and many of the elements are underrepresented. The only elements that show high \%MAU values are crania, dentaries, fibulae, and patellae.

The \%MAU values for the seven species were pooled so that we could examine the range of values for each element (Fig. 1). It is consistently the skull elements (crania [especially maxillae] and dentaries) that yield the 
TABLE 5. Weathering data for the Pit 91 sample. Regardless of taxon, bone type, and age, the majority of the bones exhibit the first three weathering stages. Numbers in parentheses refer to percentage of the total.

\begin{tabular}{|c|c|c|c|c|c|c|}
\hline Taxon & Stage 0 & Stage 1 & Stage 2 & Stage 3 & Stage 4 & Stage 5 \\
\hline \multicolumn{7}{|l|}{ Artiodactyla } \\
\hline Skull & 16 & 108 & 43 & 48 & 2 & 1 \\
\hline Axial bone & 24 & 389 & 122 & 67 & 7 & 0 \\
\hline Long bone & 11 & 154 & 59 & 52 & 7 & 1 \\
\hline Compact bone & 6 & 66 & 26 & 2 & 0 & 0 \\
\hline \multicolumn{7}{|l|}{ Perissodactyla } \\
\hline Skull & 9 & 51 & 15 & 15 & 2 & 0 \\
\hline Axial bone & 28 & 427 & 67 & 40 & 2 & 0 \\
\hline Long bone & 3 & 65 & 34 & 32 & 4 & 1 \\
\hline Compact bone & 0 & 42 & 6 & 2 & 2 & 0 \\
\hline \multicolumn{7}{|l|}{ Edentata } \\
\hline Skull & 4 & 28 & 10 & 6 & 0 & 0 \\
\hline Axial bone & 10 & 136 & 54 & 38 & 6 & 0 \\
\hline Long bone & 10 & 72 & 16 & 12 & 1 & 0 \\
\hline Compact bone & 5 & 29 & 10 & 2 & 0 & 0 \\
\hline \multicolumn{7}{|l|}{ Carnivora } \\
\hline Skull & 220 & 834 & 278 & 149 & 10 & 1 \\
\hline Axial bone & 553 & 4793 & 732 & 353 & 27 & 0 \\
\hline Long bone & 747 & 4254 & 582 & 265 & 24 & 3 \\
\hline Compact bone & 418 & 1303 & 89 & 13 & 2 & 0 \\
\hline \multicolumn{7}{|l|}{ Other Mammalia } \\
\hline Skull & 28 & 82 & 15 & 13 & 1 & 0 \\
\hline Axial bone & 11 & 91 & 21 & 21 & 1 & 0 \\
\hline Long bone & 6 & 13 & 4 & 1 & 0 & 0 \\
\hline Compact bone & 0 & 4 & 0 & 0 & 0 & 0 \\
\hline Total & $2109(11)$ & $12,941(70)$ & $2183(12)$ & $1131(6)$ & $98(1)$ & $7(0.03)$ \\
\hline \multicolumn{7}{|l|}{ Age } \\
\hline Adult & $945(11)$ & $5931(69)$ & $1182(14)$ & $471(5)$ & $52(0.6)$ & $3(0.03)$ \\
\hline Juvenile & $425(9)$ & $3302(71)$ & $470(10)$ & $406(9)$ & $26(0.6)$ & $1(0.02)$ \\
\hline
\end{tabular}

highest \%MAU values $($ mean $=0.9$, range $=$ 0.71-1.0), whereas small elements such as sacral vertebrae, caudal vertebrae, sternebrae, carpals, tarsals (other than astragalus and calcaneum), and phalanges have the lowest $\%$ MAU values $($ mean $=0.18$, range $=0.14-$ $0.24)$. The limb elements have \%MAU values that tend to be around 50\% (mean $=0.51$, range $=0.45-0.57$ )

Completeness of Skeletal Elements.-Only data from adult individuals are used in this analysis, as juveniles were scored as partial even if only unfused epiphyses were missing. Out of a total of 8586 unequivocally adult specimens from all taxa, $76 \%$ were complete. This indicates that, of the bones that were deposited at the tar seep, fully three-quarters of them were unmodified before burial.

Bone Density.-To determine if any densitymediated processes of destruction might have influenced the Pit 91 assemblage, the repre- sentation of elements relative to their density was examined for bison and horse, the only two of the fossil species for which there are pertinent density data. A regression of the $\mathrm{Bi}$ son \%MAU limb data against wildebeest (Connochaetes taurinus) bone density data revealed a significant $(p<0.0001)$ relationship between the density of an element portion and \%MAU value (Fig. 2). The elements included in this analysis are the proximal end, proximal shaft, midshaft, distal shaft, and distal end of the humerus, radius, metacarpal, femur, tibia, and metatarsal. To determine if carnivore ravaging was likely to have created the pattern of representation seen in the Pit 91 Bison assemblage, the \%MAU values of limb portions were plotted against the mean fat content of those limb portions (Fig. 3). The highly significant relationship between these two variables $(p<$ 0.0001 , Spearman's rho $=-0.854$ ) suggests that Bison carcasses were ravaged by carni- 
TABLE 6. Number of specimens assigned to each category of abrasion, separated by taxon, bone type, and age. The number in parentheses is the percentage of the total.

\begin{tabular}{|c|c|c|c|c|c|}
\hline Taxon & Absent & Minimal & Light & Moderate & Heavy \\
\hline \multicolumn{6}{|l|}{ Artiodactyla } \\
\hline Skull & 22 & 32 & 126 & 33 & 5 \\
\hline Axial & 40 & 96 & 327 & 134 & 11 \\
\hline Long bone & 44 & 51 & 123 & 53 & 13 \\
\hline Compact bone & 25 & 26 & 30 & 16 & 3 \\
\hline \multicolumn{6}{|l|}{ Carnivora } \\
\hline Skull & 283 & 349 & 623 & 203 & 34 \\
\hline Axial & 720 & 1708 & 3031 & 868 & 131 \\
\hline Long bone & 1539 & 2201 & 1618 & 459 & 57 \\
\hline Compact bone & 465 & 742 & 525 & 84 & 9 \\
\hline \multicolumn{6}{|l|}{ Edentata } \\
\hline Skull & 6 & 9 & 21 & 11 & 1 \\
\hline Axial & 12 & 61 & 114 & 47 & 10 \\
\hline Long bone & 16 & 31 & 40 & 19 & 5 \\
\hline Compact bone & 9 & 12 & 17 & 6 & 2 \\
\hline \multicolumn{6}{|l|}{ Perissodactyla } \\
\hline Skull & 8 & 15 & 52 & 16 & 1 \\
\hline Axial & 35 & 104 & 300 & 114 & 31 \\
\hline Long bone & 20 & 22 & 52 & 39 & 6 \\
\hline Compact bone & 13 & 12 & 20 & 5 & 2 \\
\hline \multicolumn{6}{|l|}{ Other Mammalia } \\
\hline Skull & 26 & 38 & 60 & 15 & 0 \\
\hline Axial & 12 & 24 & 79 & 33 & 7 \\
\hline Long bone & 0 & 4 & 11 & 6 & 3 \\
\hline Compact bone & 0 & 0 & 4 & 0 & 0 \\
\hline Total & $3295(18)$ & $5537(30)$ & $7173(39)$ & $2161(12)$ & $331(2)$ \\
\hline \multicolumn{6}{|l|}{ Age } \\
\hline Adult & $1895(22)$ & $2937(34)$ & $2950(34)$ & $686(8)$ & $114(1)$ \\
\hline Juvenile & $369(8)$ & 874 (19) & $2276(49)$ & $966(21)$ & $144(3)$ \\
\hline
\end{tabular}

vores who either dispersed or consumed the greasiest portions of the limb elements.

However, a similar analysis of Equus limb bone density and representation does not show such a strong relationship. Regression of Equus \%MAU limb data against modern Equus bone density data showed a weaker correlation (Fig. 4). Although it is significant ( $p=$ $0.0004)$, the bivariate plot shows a general

TABLE 7. A summary of the quantity of carnivore modifications found on the various types of skeletal elements from the entire sample of bones $(n=18,498)$.

\begin{tabular}{lrrrr}
\hline \hline \multicolumn{1}{c}{ Bone class } & $n$ & Score & Puncture & Notch \\
\hline Compact bone & 19 & 10 & 6 & 5 \\
Innominate/scapula & 45 & 27 & 14 & 18 \\
Long bone & 132 & 90 & 22 & 34 \\
Rib & 114 & 70 & 26 & 23 \\
Skull & 23 & 7 & 4 & 12 \\
Vertebra & 98 & 39 & 23 & 44 \\
Total: & 431 & 243 & 95 & 136 \\
\hline
\end{tabular}

scatter of points. These data suggest that unlike Bison, the representation of Equus limb element portions was not strongly influenced by a density-mediated process. Mean fat content of Equus limb elements has not been published, but marrow cavity volume for the limb bones (Outram and Rowley-Conwy 1998) plotted against \%MAU values show a weak, nonsignificant relationship (Fig. 5). Of course, marrow cavity volume is not the same as either marrow mass or quality, but Outram and Rowley-Conwy (1998) found that it provides the same rank order of elements, and is more consistently measured than marrow mass. Notably, their study indicated that the femur, humerus, and radius had the greatest cavity volumes and marrow masses. These elements are not underrepresented in Pit 91 (all have $\%$ MAU values greater than 0.60 ), and thus the skeletal-element representation of Equus limb bones does not appear to be indicative of car- 
TABLE 8. Taxonomic information for the specimens that exhibit carnivore tooth marks.

\begin{tabular}{|c|c|c|c|c|c|}
\hline Order & Family & Genus & $\begin{array}{c}\text { No. of } \\
\text { tooth-marked } \\
\text { specimens }\end{array}$ & Total NISP & $\begin{array}{l}\text { Proportion } \\
\text { of NISP with } \\
\text { tooth marks }\end{array}$ \\
\hline Artiodactyla & & & 1 & 28 & 0.04 \\
\hline Artiodactyla & Antilocapridae & Capromeryx & 1 & 71 & 0.01 \\
\hline Artiodactyla & Bovidae & Bison & 75 & 1004 & 0.07 \\
\hline Artiodactyla & Camelidae & Camelops & 2 & 38 & 0.05 \\
\hline Artiodactyla & Cervidae & & 1 & 7 & 0.14 \\
\hline Artiodactyla & Cervidae & Odocoileus & 2 & 21 & 0.10 \\
\hline Carnivora & Canidae & Canis & 112 & 7915 & 0.01 \\
\hline Carnivora & Felidae & Panthera & 5 & 188 & 0.03 \\
\hline Carnivora & Felidae & Smilodon & 155 & 7312 & 0.02 \\
\hline Carnivora & Ursidae & Arctodus & 3 & 86 & 0.03 \\
\hline Edentata & & & 2 & 6 & 0.33 \\
\hline Edentata & Megatheriidae & Nothrotheriops & 1 & 52 & 0.02 \\
\hline Edentata & Mylodontidae & Paramylodon & 14 & 386 & 0.04 \\
\hline Herbivore & & & 8 & 96 & 0.08 \\
\hline Mammalia & & & 3 & 204 & 0.01 \\
\hline Pecora & & & 1 & 1 & 1.00 \\
\hline Perissodactyla & Equidae & Equus & 44 & 849 & 0.05 \\
\hline Unknown & & & 1 & 6 & 0.17 \\
\hline
\end{tabular}

nivore ravaging, at least, not to the extent seen in the Bison assemblage.

\section{Discussion}

The taphonomic data collected for this study can be used to identify the postmortem processes that affected the larger animals that became trapped in the Pit 91 asphalt deposit. The majority of the more than 18,000 specimens examined showed little or no weathering, indicating that skeletal elements were not exposed on the surface for long. Abrasion data

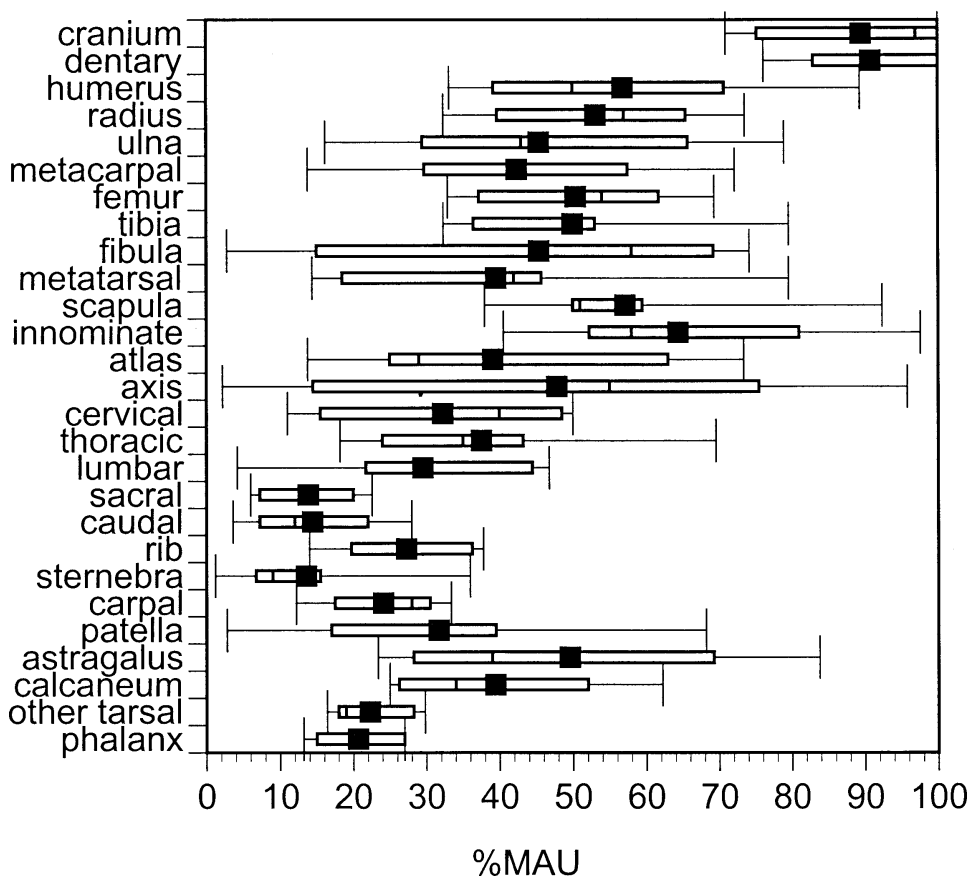

FIGURE 1. The \%MAU values for each element pooled for the seven most common large mammals from Pit 91 . The black box represents the means, and the vertical lines represent the endpoints of the ranges. The open horizontal box encloses the central $50 \%$ of the data. 


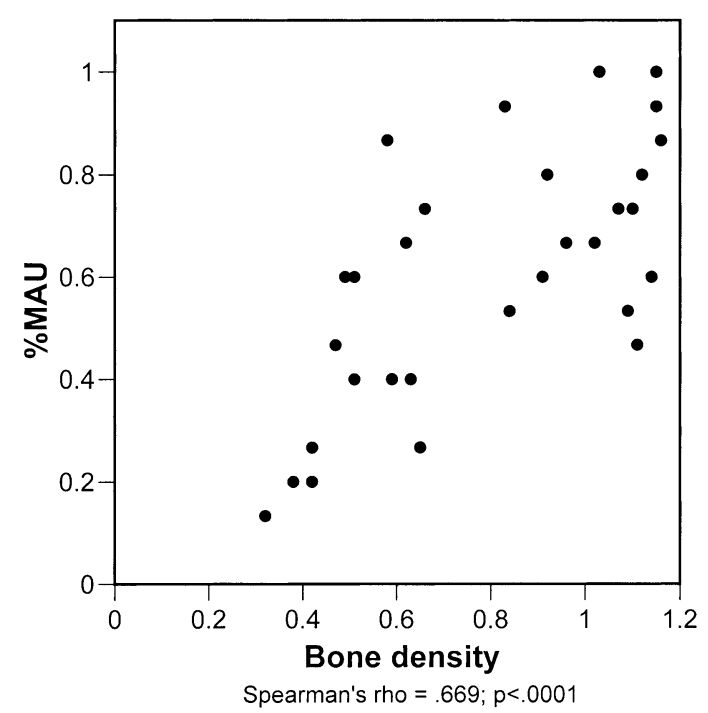

FIGURE 2. Bison \%MAU values for limb portions (proximal epiphysis, proximal shaft, midshaft, distal shaft, and distal epiphysis of the humerus, radius, metacarpal, femur, tibia, and metatarsal) plotted against Connochaetes bone density values from Lam et al. 1999.

suggest that fluvial action did not significantly influence the composition of the bone assemblage from Pit 91. The erosion of surface bone is not common in this assemblage, as $86 \%$ of the specimens examined show little, minimal, or no abrasion at all. Although the area of deposition includes stream channels, it

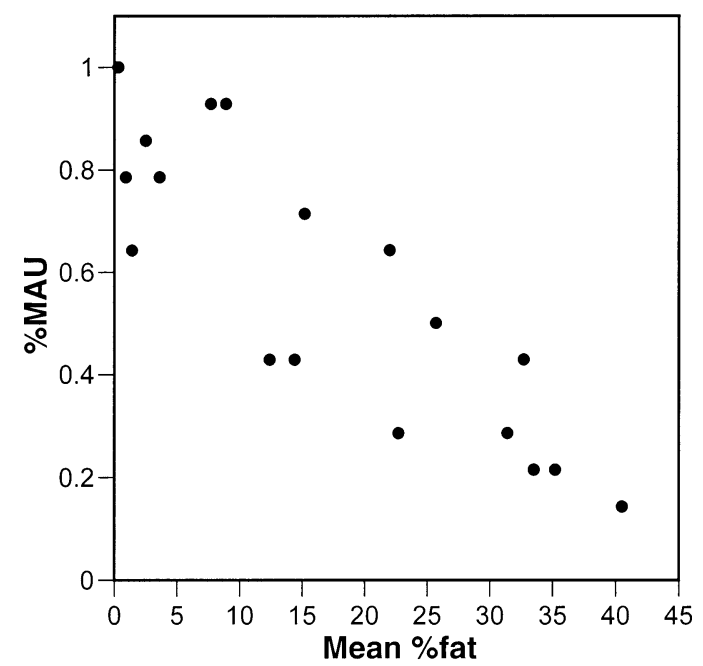

Spearman's rho $=.854 ; \mathrm{p}<.0001$

FIgURE 3. Bison \%MAU values for limb portions (same as in Fig. 2) plotted against mean percentage of fat values found in Bison limb bones from Brink 1997.

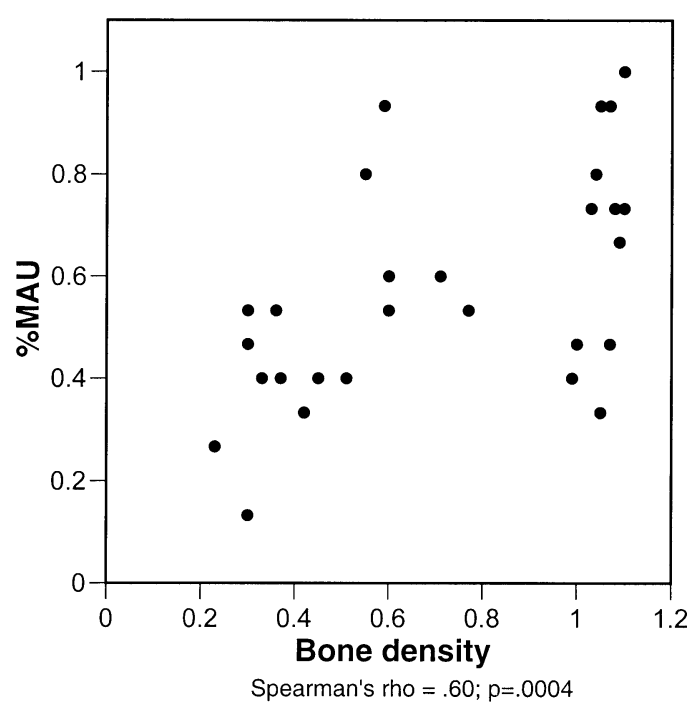

FIgURE 4. Equus \%MAU values for limb portions (same as in Fig. 2) plotted against Equus bone density values from Lam et al. 1999.

seems that once partial or entire carcasses were mired in asphalt, they resisted movement by water. The abrasive effects of asphalt on bone are unknown, and future actualistic studies might indicate that the small amounts of observed abrasion are the result of erosion of surface bone by asphalt rather than water.

However, in the short time between death

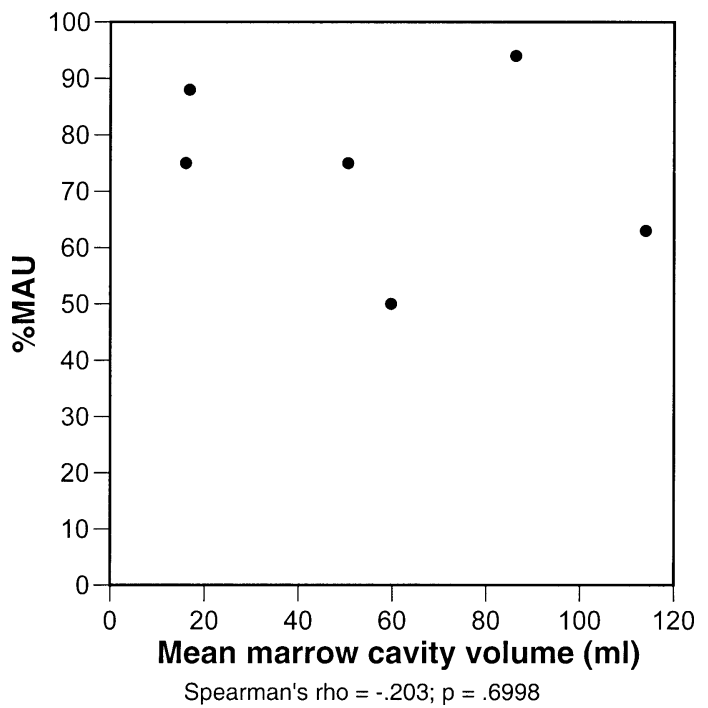

FIgURE 5. Equus \%MAU values for limb elements (humerus, radius, metacarpal, femur, tibia, metatarsal) plotted against mean marrow cavity volume $(\mathrm{ml})$ from three modern horses; data from Outram and RowleyConwy 1998. 
and burial, it is clear that some taphonomic process was affecting carcasses, because complete skeletons are rare, if not entirely absent. Among the seven most common species, cranial elements (skull and mandible) predominate (Fig. 1). Skeletal elements that are most often missing from these species are the small bones, (such as sternebrae, tarsals, carpals, and smaller vertebrae such as sacral and caudal elements), though larger elements such as limb bones tend to be represented only half as often as expected.

Carnivore ravaging can produce patterns of skeletal representation similar to that documented for Pit 91. If intense carnivore ravaging occurred during the formation of the Pit 91 assemblage, skulls and mandibles are expected to be the most common elements, and that is indeed the case. When the MNE values for each of the seven most common species were scaled to reflect completeness of skeletons, all but one species had either cranium or dentary as yielding the highest MAU. The single exception is Equus, in which the axis yields the highest MAU value. This cervical vertebra is so tightly attached to the skull by ligaments that it is often considered part of the head complex (Haynes 1982), and so does not nullify our hypothesis.

Many observers of carnivore ravaging behaviors at kill sites have noted that carnivores often remove a limb from a carcass and transport it to a safer place for feeding (e.g., Haynes 1982; Blumenschine 1988). Therefore, we predicted that limb bones would be present only half as often as expected, and indeed, the $\%$ MAU values for most of the limb bones of the seven species tend to be around $50 \%$. We suggest that only half of the limb elements are represented in Pit 91 because the other half, representing the half of the carcass that was not in contact with the ground, was carried off by carnivores. The limbs on one side of the carcass were presumably mired in the asphalt, and thus could not be carried off or were not desirable because of the asphalt contamination. Notably, skeletal representation data do not show that distal limb bones are better represented than more proximal elements. This might be expected if trapped animals usually sank in feet first, leaving their torsos and heads exposed to carnivores. However, Table 4 does not show a pattern of greater representation of distal relative to more proximal elements (compare radii with humeri, tibiae with femora, metapodials with femora or humeri). Instead, it seems that animals usually fell to one side as they struggled in the asphalt.

The predominance of half skeletons implies that many of the carnivores that came to feed on trapped animals at Rancho La Brea were successful at removing elements from the asphalt and did not become trapped themselves. Interestingly, Haynes (1982) noted that wolves carry carcass parts back to their dens in the summertime, when their young, born in early spring, are old enough to eat meat. Speculating that dire wolves had a similar reproductive schedule, we might expect that they also were removing parts from carcasses trapped in asphalt deposits during the summer, when the seeps are at their stickiest (Shaw and Quinn 1986; Quinn 1992).

The overall pattern of skeletal part representation indicates many missing elements for the most abundant species from Pit 91, especially the bison. The significant correlation between bone density and element representation in this species suggests that carnivores were responsible for eliminating the least dense elements. This conclusion is further supported by the relationship between element representation and bone grease content, which showed that the least common elements were those that contained the most bone grease. However, a different pattern is seen in the skeletal part representation of the other common herbivore, the horse. Equus elements show higher \%MAU values, and weaker correlations between the elements present and both bone density and marrow content. Lam et al.'s 1999 study of bone density among species of bovids and equids concluded that "the similarity in bone density patterns [between these two groups]... indicates that differences in bone survivorship between them are far more likely to be attributable to behavioral agents than to density-mediated destruction (Lam et al. 1999: p. 359). We therefore conclude that the different pattern of skeletal-element representation at La Brea is more likely the result of carnivore preference for Bison. 
Apparently, La Brea carnivores were less interested in consuming Equus skeletal elements, perhaps because the marrow content in their limb bones is of lower yield relative to that of artiodactyls (Blumenschine and Madrigal 1993; Outram and Rowley-Conwy 1998). The nutrient content of Paramylodon bones is unknown, but their pattern of more complete representation in the Pit 91 assemblage suggests that, compared with the other herbivore species, sloth carcasses were less attractive and less vulnerable to carnivores. Because many elements are missing from the four carnivore species profiles and a small percentage of carnivore bones exhibit tooth marks, it appears that these species were also consumed, which is intriguing because extant carnivores rarely feed on other large carnivores even when they are available.

Our expectation of little on-site ravaging was supported by data on carnivore modification and completeness of skeletal elements. The actual amount of carnivore modification on the bones is low, less than $2 \%$, and the majority of the adult bones are complete. A tar seep was not likely to have been a comfortable place for a carnivore to consume a carcass, and the low \%MAU values for many elements suggests that carnivores were more likely to have taken body parts away from the tar seep for consumption. These data highlight the unique nature of this depositional environment, emphasizing its differences from modern kill sites.

\section{Conclusion}

The wealth of material recovered from the asphalt deposits of Rancho La Brea has long been appreciated for providing information about late Pleistocene fauna and flora of southern California. However, research using the collections has been limited by a lack of data on the taphonomic history of the fossil deposits. Our taphonomic analysis of a sample of over 18,000 specimens from Pit 91 indicates rapid burial and a strong overprint of carnivore activity. Rapid burial is supported by the fact that over $90 \%$ of the bones exhibit little or no weathering. Although the bones themselves have few carnivore tooth marks, the patterns of skeletal-element abundance in- dicate that many elements are missing from the assemblage. Moreover, those elements that are missing appear to be those that are most attractive to carnivores because of their low density and high nutrient content (at least for the most common herbivore for which such data are available). Carnivores and herbivores show a comparable lack of complete preservation, suggesting that both were similarly subject to carnivore feeding activity. From these results we conclude that the large mammal assemblage of Pit 91 has been substantially biased by the activities of carnivores.

\section{Acknowledgments}

We would like to thank M. Spencer, E. Scott, C. W. Marean, and R. K. Wayne for their helpful comments on the research presented here, and C. Shaw and S. Cox for their assistance in using the Page Museum collections. Many individuals participated in data collection, including A. Friscia, K. Gouine, J. Lee, and T. Sacco, and their efforts are greatly appreciated. We thank A. K. Behrensmeyer and C. W. Marean for contributing comparative taphonomic material. This manuscript was improved by the comments of R. Blumenschine and R. L. Lyman. This research was supported by National Science Foundation grant IBN9405916.

\section{Literature Cited}

Akersten, W. A., C. A. Shaw, and G. T. Jefferson. 1983. Rancho La Brea: status and future. Paleobiology 9:211-217.

- 1978. Taphonomic and ecologic information from bone weathering. Paleobiology 4:150-162.

Blumenschine, R. J. 1986. Carcass consumption sequences and the archaeological distinction of scavenging and hunting. Journal of Human Evolution 15:639-659.

-1988. An experimental model of the timing of hominid and carnivore influence on archaeological bone assemblages. Journal of Archaeological Science 15:483-502.

Blumenschine, R. J., and T. C. Madrigal. 1993. Variability in long bone marrow yields of East African ungulates and its zooarchaeological implications. Journal of Archaeological Science 20:555-587.

Blumenschine, R. J., C. W. Marean, and S. D. Capaldo. 1996. Blind tests of inter-analyst correspondence and accuracy in the identification of cut marks, percussion marks, and carnivore tooth marks on bone surfaces. Journal of Archaeological Science 23:493-507.

Brink, J. W. 1997. Fat content in leg bones of Bison bison, and applications to archaeology. Journal of Archaeological Science 24:259-274.

Bromage, T. G. 1984. Interpretation of scanning electron microscopic images of abraded forming bone surfaces. American Journal of Physical Anthropology 64:161-178. 
D'Andrea, A. C., and R. M. Gotthardt. 1984. Predator and scavenger modification of recent equid skeletal assemblages. Arctic 37:276-283.

Eisenberg, J. 1981. The mammalian radiations. University of Chicago Press, Chicago.

Fisher, J. W., Jr. 1995. Bone surface modifications in zooarchaeology. Journal of Archaeological Method and Theory 2:7-68.

Gilbert, J. Z. 1927. The bone drift in the tar-beds of Rancho La Brea. Bulletin of the Southern California Academy of Sciences 26:54-66.

Harris, J. M., and G. T. Jefferson. 1985. Rancho La Brea: treasures of the tar pits. The Natural History Museum of Los Angeles County, Los Angeles.

Haynes, G. 1980. Evidence of carnivore gnawing on Pleistocene and Recent mammalian bones. Paleobiology 6:341-351.

1982. Utilization and skeletal disturbances of North American prey carcasses. Arctic 35:266-281.

-1983. A guide for differentiating mammalian carnivore taxa responsible for gnaw damage to herbivore limb bones. Paleobiology 9:164-172.

Lam, Y. M., X. Chen, C. W. Marean, and C. J. Frey. 1998. Bone density and long bone representation in archaeological faunas: comparing results from CT and photon densitometry. Journal of Archaeological Science 25:559-570.

Lam, Y. M., X. Chen, and O. M. Pearson. 1999. Intertaxonomic variability in patterns of bone density and the differential representation of bovid, cervid, and equid elements in the archaeological record. American Antiquity 64:343-362.

Lyman, R. L. 1994. Vertebrate taphonomy. Cambridge University Press, Cambridge.

Marcus, L. F. 1960. A census of the abundant large Pleistocene mammals from Rancho La Brea. Contributions in Science, Los Angeles County Museum of Natural History 38:1-11.

Marcus, L. F., and R. Berger. 1984. The significance of radiocarbon dates for Rancho La Brea. Pp. 159-183 in P. S. Martin and R. G. Klein, eds. Quaternary extinctions. University of Arizona Press, Tucson.

Marean, C. W., and C. L. Ehrhardt. 1995. Paleoanthropological and paleoecological implications of the taphonomy of a sabertooth's den. Journal of Human Evolution 29:515-547.

Marean, C. W., and L. M. Spencer. 1991. Impact of carnivore ravaging on zooarchaeological measures of element abundance. American Antiquity 56:645-658.
Marean, C. W., L. M. Spencer, R. J. Blumenschine, and S. D. Capaldo. 1992. Captive hyaena bone choice and destruction, the schlepp effect and Olduvai archaeofaunas. Journal of Archaeological Science 19:101-121.

Miller, G. J. 1969. A study of cuts, grooves, and other marks on recent and fossil bone: I. Animal tooth marks. Tebiwa 12:2026.

1975. A study of cuts, grooves, and other marks on recent and fossil bone. II. Weathering cracks, fractures, splinters, and other similar natural phenomena. Pp. 211-227 in E. Swanson, ed. Lithic technology. Mouton, The Hague.

Outram, A., and P. Rowley-Conwy. 1998. Meat and marrow utility indices for horse (Equus). Journal of Archaeological Science 25:839-849.

Quinn, J. P. 1992. Rancho La Brea: geologic setting, late Quaternary depositional patterns and mode of fossil accumulation. Pp. 221-232 in E. G. Heath and W. L. Lewis, eds. The regressive pleistocene shoreline, southern California. Guidebook No. 20. South Coast Geological Society, Santa Ana, Calif.

Scott, E. 1989. Skeletal remains of Equus from the Page Museum Salvage, Rancho La Brea: a preliminary report. Current Research in the Pleistocene 6:78-81.

Shaw, C. A. 1982. Techniques used in excavation, preparation, and curation of fossils from Rancho La Brea. Curator 25:6367.

Shaw, C. A., and J. P. Quinn. 1986. Rancho La Brea: a look at coastal southern California's past. California Geology 29:123133.

Shipman, P., and J. Rose. 1988. Bone tools: an experimental approach. In S. L. Olsen, ed. Scanning electron microscopy in archaeology. British Archaeological Reports International Series 452:303-335.

Stock, C. 1929. Significance of abraded and weathered mammalian remains from Rancho La Brea. Bulletin of the Southern Californa Academy of Sciences 28:1-5.

Stock, C., and J. M. Harris. 1992. Rancho La Brea, a record of Pleistocene life in California. Natural History Museum of Los Angeles County Science Series No. 37.

Van Valkenburgh, B., and F. Hertel. 1993. Tough times at La Brea: tooth breakage in large carnivores of the late Pleistocene. Science 261:456-459.

Woodard, G. D., and L. F. Marcus. 1973. Rancho La Brea fossil deposits: a re-evaluation from stratigraphic and geological evidence. Journal of Paleontology 47:54-69. 